\title{
Readiness of Kampala International University Doctoral Students for Open and Distance Education
}

\author{
F. E. K. Bakkabulindi, ${ }^{1, *}$, F. N. Mulumba ${ }^{2}$, B. Aluonzi ${ }^{2}$, C. Oketch ${ }^{2} \&$ A. Taibu ${ }^{2}$
}

(C) Uganda Martyrs University

\begin{abstract}
This study examined the readiness of Kampala International University Doctoral Students for open and distance education and related this readiness to gender, income and perceived user friendliness of ICT. Using a self-administered questionnaire, data were collected from 43 of these students and analysed using means, t-test and correlation analyses. The findings were that there is relationship between each of gender, income and perceived user friendliness of ICT and readiness for open and distance learning. However, only the relationship between perceived user friendliness of ICT and the said readiness was found to be statistically significant. Therefore, it was concluded that, if they are to be ready for open and distance education, the students deserve equal encouragement, exposure and training with respect to the use of ICT, notwithstanding their gender and income differentials.
\end{abstract}

Keywords $\cdot$ E-learning $\cdot$ Doctoral pedagogies $\cdot$ Technology adoption

Disposition des Etudiants en Doctorat a l'Université Internationale de Kampala pour une Education Ouverte et par Correspondance - Résumé - Cette étude a examiné la disposition d'étudiants en Doctorat de l'Université International de Kampala pour l'éducation ouverte et par correspondance et ainsi relier cette disposition au genre, revenu et l'usage perçu aisé de Technologie and Communication Informatiques (TCI). Usant un questionnaire auto-administré, les données ont été collectées a partir de 43 de ces étudiants et analysées en usant les moyennes, test-t, et analyses de corrélation. Les résultats ont montré qu'il y a une relation entre chacun de genre, revenu et usage perçu aisé de TCI ainsi que la disposition pour l'éducation ouverte et par correspondance. Cependant, seule la relation entre l'usage perçu aisé de TCI et ladite disposition était révélée être statistiquement signifiante. C'est pourquoi, il a été conclu que, s'ils étaient appelés a être prêt pour l'éducation ouverte et par correspondance, ces étudiants méritent un même encouragement, exposition et formation en ce qui concerne l'usage de TCI, sans pour autant négliger leur différence dans le genre et revenu. Mots Clé $\cdot$ Enseignement par Informatique (I-Enseignement) $\cdot$ Pédagogies doctorales $\cdot$ Adoption technologiques

\section{Introduction}

Traditional university education entailed students and their teachers staying in one locality, engaging in what we may term "localized and closed education". However due to the Digital Revolution, this is no longer the case. Students and their teachers are increasingly being challenged

\footnotetext{
${ }^{1}$ Makerere University, *Corresponding author: fekbakkabulindi@isae.mak.ac.ug

${ }^{2}$ Kampala International University
} 
to engage in "open and distance education" involving several people in several locations in the world attending joint virtual classes. Such internationalized education is facilitated by ICT particularly the Internet. Being an effective student in such an international context calls for a student to be electronically ready (e-ready) that is to be able to use ICT resources such as Internet.

The questions for this study were: how ready were doctoral students in Kampala International University (KIU) for open and distance education in so far as they used the Internet? How did this readiness differ with gender, income level and perceived user friendliness as suggested by innovation diffusion and adoption theorists such as Rogers (2003)? In answer, this paper reports on a survey carried out with the purpose of not only establishing levels of readiness of doctoral students in the University for Open and Distance education in so far as they used the Internet but also to link the same to gender, income level and perceived user friendliness.

\section{Literature}

\section{Gender and Readiness for Innovations}

Gender comprises a range of differences between men and women, extending from the biological to the social roles a woman has to play like caring for the children, cooking, fetching water and firewood, in addition to cultivation. Ssekiboobo (1995 cited in Basiisa, 1999) argues that such roles may hinder her from easily adopting to technology use. According to Kato (2000), the marginalization of women in regard to technology adoption and transfer is reinforced by the African cultural system which requires women to remain at home while husbands attend seminars, yet they do not always teach women what they have learnt in extension meetings.

Women do not have accessibility to the key productive resources such as capital, as well as being underprivileged in education and knowledge. Mwebesa (1997) observes that technological changes are not usually aimed at women at all, and that large scale development projects and their attendant technology rarely include policy regarding women; that sexist bias was the most important factor explaining the inability of women to take advantage of new technology offered; that appropriate technology programmes reveal that many projects do not achieve positive results for women's lives; that in many projects, even technology introduced for the benefit of women has been co-opted by men for their own use.

\section{Income Level and Readiness for Innovations}

On the importance of income in innovation adoption, Schiffman and Kanuk (2004) observe that "consumers innovators have... higher personal or family incomes, and are more likely to have higher occupational statuses... than late adopters or non-innovators" (p. 538). According to Morales-Gomez and Melesse (1998), access to Internet and other ICTs is only open to a small fraction of the population, a phenomenon which is a function of income; Internet users tend to have above average income. They further assert that the situation is even more dramatic in developing countries where the income gap is exorbitant; where literacy rates are remarkably lower; and where the users of telecommunication technologies are likely to belong to modern elite.

\section{Perceived User Friendliness and Readiness for Innovations}

User friendliness (or usability, ease of use or non-complexity) is the degree to which an innovation is perceived as relatively easy to understand and use (Rogers, 2003). Lunkuse (2004) observes that technology users perceive a technology as user-friendly if it is easy to learn, become skilful, flexible and is controllable. Dawa (2004) refers to the ease of use of an innovation as its usability, quoting the International Standards Organisation (ISO 9241-11) as defining usability as "the extent to which a product can be used by specified users to achieve specified goals with effectiveness, efficiency and satisfaction in a given context" (Dawa, 2004: 43). Eason (1988) defines usability of a system as the system offering its functionality in such a way that the planned users will be able to master and exploit it without undue strain on their capacities and skills. It is in this domain that the importance of user friendliness, ease of use and ease of learning are usually emphasized. The 
complexity of an innovation, as perceived by members of a social system, is negatively related to its rate of use (Rogers, 2003).

\section{Hypotheses}

From the literature, the research hypothesized that gender related to readiness for open and distance education in such a way that males were better. Each of income level and perceived user friendliness was postulated to be a positive correlate of readiness for open and distance education.

\section{Methods}

Using a quantitative correlational survey design, data were collected using a self-administered questionnaire with questions or items of relevance in this paper, namely a question on gender and income level. The questionnaire had three items on perceived user friendliness of ICT $(\alpha=0.912)$ and eight items on use of Internet $(\alpha=0.859)$, and hence readiness for open and distance education. The questionnaire was reliable for the study as both alpha coefficients were above 0.5 (Cronbach, 1971). Using the said questionnaire, data were collected from a sample of 43 doctoral students in Kampala International University. The data were analysed at univariate level using means. Hypotheses were then tested using two bivariate analyses, namely t test and correlation analyses.

\section{Findings and Discussion}

\section{Background of Respondents}

Of the 43 respondents, according to specialisation, Education Management contributed biggest (32.6\%), followed by Business Management and Public Management each contributing 27.9\%; and trailed by Management information Systems (11.6\%). In terms of age, the majority $(53.9 \%)$ were aged between 30 and 40 years, followed by those below 30 years $(33.3 \%)$, and the rest $(12.8 \%)$ were above 40 years of age. With regard to gender, males $(76.7 \%)$ dominated females $(23.3 \%)$, while regarding income level, most respondents perceived themselves as being of medium income $(81.0 \%)$, followed by $16.7 \%$ of low income and one $(2.4 \%)$ of high income. Regarding possession of qualification in ICT, the majority $(64.3 \%)$ held none, vis-à-vis $35.7 \%$ with one. With respect to current job, the majority (50.0\%) were both teachers and administrators, followed by $40.5 \%$ in teaching only and the rest $(9.5 \%)$ in administration.

\section{Readiness for Open and Distance Education}

The dependent variable in the study, readiness for open and distance education, conceptualized as level of use of Internet, was a multi-dimensional variable made of eight items, each scaled $1=$ Very rarely or never, including never heard of it; 2 = Rarely use; 3 = Neither rarely nor regularly; 4 $=$ Regularly; and 5 = Very regularly. Pertinent means are given in Table 1.

Table 1: Means on Readiness for Open and Distance Education

\begin{tabular}{lcl}
\hline Indicator of Readiness: Level of Use of.... & Mean & Level of Use \\
\hline Email & 4.39 & Regular \\
Web surfing & 4.13 & Regular \\
Bulletin board, mailing lists and discussion groups & 2.81 & Neither rare nor regular \\
Computer conferencing systems & 2.24 & Rare \\
Video conferencing systems & 1.92 & Rare \\
Electronic journals and newsletters & 2.74 & Neither rare nor regular \\
Electronic databases & 2.28 & Rare \\
On-line library catalogues & 2.42 & Rare \\
\hline
\end{tabular}

According to Table 1, the only Internet facilities with appreciable levels of use, were email and web surfing in that order, suggesting low levels of use of Internet by the respondents, and hence low levels of readiness for open and distance education. An overall average index ("Ready" from the eight items in Table 1 ) had a mean $=2.86$, which suggested that overall, respondents neither rarely 
nor regularly used Internet facilities, and hence had fair levels of readiness for open and distance education. This finding was at least partially in line with those of earlier researchers who found low levels of utilization of computers by students in universities in Uganda. For example Nassanga (2001) found that students in Makerere hardly participate in ICT usage and management. Gakibayo (2001) established low levels of use of Internet by students in Mbarara University of Science and Technology, while Wakanyasi (2002) found the same true in Nkumba University. Pertinent conclusions and recommendations are also given hypothesis by hypothesis:

\section{Gender and Readiness for Open and Distance Education}

The first hypothesis was that gender related to readiness for open and distance education or use of Internet, with males being better. Summary statistics and t-test results there from, are given in Table 2.

Table 2: Statistics and t Test on Readiness for Open and Distance Education by Gender

\begin{tabular}{lccccc}
\hline Gender & Count & Mean & Std Dev & T & P \\
\hline Female & 10 & 3.06 & 0.88 & 0.877 & 0.387 \\
Male & 27 & 2.79 & 0.80 & & \\
\hline
\end{tabular}

Although means in Table 2 suggested that females were more ready for open and distance education than males, the pertinent $t$ value was small $(p>0.05)$. Thus at the five percent, the null hypothesis was upheld. While the study finding negated the pertinent hypothesis, it was similar to that of Ehikhamenor (1999), but disagreed with others (e.g. Mburu, Massimo and Mutua, 2000). The possible explanation for the anomalous study finding is that levels of readiness for open and distance education or use of Internet could be so low among doctoral students in the University that they cut across the gender divide. The study thus concluded that any assistance with respect to Internet resources should be availed to females and males equally. Hence the recommendation that relevant stakeholders (such as the Directorate of ICT) give both female and male doctoral students in the University, equal training, exposure and/ or encouragement with respect to Internet resources.

\section{Income Level and Readiness for Open and Distance Education}

The second hypothesis in the study was that income level was positively related with readiness for open and distance education or use of Internet. Respondents were thus to rate themselves on income on a scale where $1=$ Low; 2 = Medium; and 3 = High. However, only one individual gave a selfrating in the third category, prompting the writers of this report to ignore that respondent, leaving only two categories of respondents. Table 3 gives pertinent summary statistics and t-test results.

Table 3: Statistics and $t$ Test on Readiness for Open and Distance Education by Income Level

\begin{tabular}{lccccc}
\hline Income Level & Count & Mean & Std Deviation & $\mathbf{t}$ & $\mathbf{P}$ \\
\hline Low & 6 & 3.13 & 0.70 & 0.806 & 0.426 \\
Medium & 30 & 2.83 & 0.85 & & \\
\hline
\end{tabular}

According to means in Table 3, readiness for open and distance education seemed to fall with income, which however was not supported by the small $F$ value $(p>0.05)$. Thus the null hypothesis was accepted at the five percent level of significance. Not only was this finding inconsistent with the study hypothesis, but also inconsistent with findings of several other studies (e.g. Matovu, 2003; Nafuna, 2002). The finding challenged the theoretical assertion that the higher the income, the easier it is for an individual to acquire personal ICT facilities, and to get informal exposure to ICT through ICT magazines and newspapers (Moralez-Gomez and Melesse, 1998).

The possible explanation for this could be that students with more financial ability to acquire Internet facilities tend to be older, making their advanced age to militate against eagerness to go in for the said resources. The opposite may be true for less financially able students. This inconclusive debate raises a gap for future researchers to consider. In the interim however, the study concluded that all doctoral aspirants in the University irrespective of income level deserve same treatment in the area of readiness for open and distance education or use of Internet. Hence the recommendation that Top Management and Directorate of ICT and other relevant stakeholders give all of them equal pertinent training, exposure and/ or encouragement, regardless of their income level. 


\section{Perceived User Friendliness of ICT and Readiness for Innovations}

Perceived user friendliness of ICT was conceptualized as three items, pertaining to perceived ease of use of new hardware, software and communication facilities, respectively. All items or questions were Likert-scaled in such a way that a minimum of 1 stood for the worst case scenario (i.e. $1=$ Strongly disagree), 2 = Disagree, $3=$ Neutral, 4 = Agree to a maximum of 5 which stood for the best case scenario (i.e. $5=$ Strongly agree). Table 4 gives descriptive statistics there from.

Table 4: Means on Perceived User Friendliness of ICT

\begin{tabular}{llll}
\hline Indicators of User Friendliness & Mean & Category & Overall \\
\hline I find it easy to learn to use new hardware & 3.49 & Neutral & Mean $=3.50$ \\
I find it easy to learn to use new software & 3.40 & Neutral & Agree \\
I find it easy to learn to use new communication facilities & 3.62 & Agree & \\
\hline
\end{tabular}

Means in Table 4 suggested that respondents perceived communication facilities easiest to use (Mean $=3.62$, corresponding to "Agree"), followed by hardware (Mean $=3.49$, corresponding to "Neutral") and lastly software (Mean $=3.40$, corresponding to "Neutral"). However, overall, the respondents had a rather positive perception of user friendliness of ICT (Overall mean $=3.50$, corresponding to "Agree"). Pearson's linear correlation coefficient (PLCC) of the two numerical indexes ("Ready" and "Ufriend" from Tables 1 and 4 respectively) turned out to be $r=0.381, p=$ 0.022 indicating a positive co-relation $(r>0)$ which indeed was big $(\mathrm{p}<0.05)$ leading to rejection of the null hypothesis and acceptance of the alternative hypothesis to the effect that perceived user friendliness significantly positively related with use of Internet and hence readiness for open and distance education at five percent significance level.

This finding was in agreement with other researchers, such as Kiiza (2003) who empirically established that perceived ease of use was a major factor in acceptance of automatic teller machines; and Mugweri (2000) who established that perceived user friendliness curtailed implementation of networks in the Ministry of Finance, Planning and Economic Development in Uganda. The conclusion was that the more doctoral students perceived ICT to be user friendly, the more they will use the Internet, and hence the more ready they will be for open and distance education. Hence the recommendation that the University (especially Directorate of ICT), enhance perceived user friendliness of ICT by doctoral students via ICT training.

\section{References}

Basiisa, M. C., 1999. Farmer characteristics influencing adoption of organic farming techniques among partner farmers of Africa 2000 Network in Kasese District Uganda. Unpublished Masters of Science (Agric Ext. Educ.) dissertation, Makerere University, Kampala, Uganda.

Cronbach, L. J., 1971. Test validation. In: Educational measurement, L. J. Cronbach, L. J. (Ed.) American Council on Education, Washington, 1971, pp. 443--597.

Dawa, S., 2004. Information technology personnel competencies and computer-based information system usability in Uganda. Unpublished Master of Bus. Adm. Dissertation, Makerere University, Kampala, Uganda.

Eason, K., 1988. Informational technology and organizational change. London: Taylor and Francis.

Ehikhamenor, F. A., 1999. Cognitive information foundation of university students: index of ICT in Nigeria. Information Technology for Development, 8 (3), 134-144.

Gakibayo, A., 2001. Internet use in academic institutions: a case of Mbarara University of Science and Technology. Unpublished Bachelors of Library and Info. Sc. dissertation, Makerere University, Kampala, Uganda.

Kato, E., 2000. Factors affecting adoption of K131 bean variety by women in Luuka County, Iganga District in Uganda. Unpublished Masters of Science (Agric. Econ.) dissertation, Makerere University, Kampala, Uganda. 
Kiiza, C. K. H., 2003. Application of the Technology Acceptance Model on use of electronic payment systems in Uganda: the case of automated teller machines. Unpublished Masters of Science (Acc. \& Fin.) dissertation, Makerere University, Kampala, Uganda.

Lunkuse, F., 2004. Adoption of technological innovations in Uganda's agricultural industry. Unpublished Masters of Bus. Adm. Dissertation, Makerere University, Kampala, Uganda.

Matovu, J., 2003. Information technology issues in Uganda's education sector. Uganda Journal of Education, 4, 9-23.

Mburu, P. T., Massimo, S. K., Mutua, K., 2000. How are Internet facilities being used in Botswana? Makerere Business Journal, pp.81-98: Summary of papers presented at the $7^{\text {th }}$ Annual International Management Conference on the theme: Coping with economic and technological change in the New Millennium, organised by Makerere University Business School, at Kampala, December 4-7, 2000.

Moralez-Gomez, D., Melesse, M., 1998. Utilising information and communication technologies for development: social dimensions. Information Technology for Development, 8 (1), 3-13.

Mugweri, R A., 2000. Opportunities and challenges of exploiting ICT networks to improve efficiency and effectiveness in government operations: a case study of Ministry of Finance, Planning and Economic Development. Unpublished Masters of Science (Info Sc.) dissertation, Makerere University, Kampala, Uganda.

Mwebesa, J., 1997. Impact of technological innovation on rural women's agricultural activities: a case of the solar drier. Unpublished Masters of Arts (Women Studies) dissertation, Makerere University, Kampala, Uganda.

Nafuna, S. A., 2002. Impact of Internet service providers on electronic information provision in Uganda: A study of selected ISPs in Kampala. Unpublished Bachelor of Library and Information Science dissertation, Makerere University, Kampala, Uganda.

Nassanga, M., 2001. Students' participation in ICT usage and management: A case study of East African School of Library and Info Science. Unpublished Bachelors of Library and Information Science dissertation, Makerere University, Kampala, Uganda.

Rogers, E. M., 2003. Diffusion of innovations. Fifth edition. New York: Free Press.

Schiffman, L. G., Kanuk, L. L., 2004. Consumer behaviour. Eighth edition. New Delhi: PrenticeHall of India.

Wakanyasi, N., 2002. Capacity utilization of information technology in organisations: a case study of Nkumba University. Unpublished Masters of Bus. Adm. Dissertation, Nkumba University, Entebbe, Uganda.

\section{Author Biography}

Doctor Fred Edward K. Bakkabulindi is a Lecturer at the East African School of Higher Education Studies and Development, Makerere University College of Education. His research interests focus on doctoral pedagogies, educational measurement and correlates of innovation adoption in institutions of higher learning. F. N. Mulumba, B. Aluonzi, Chrizestom Oketch and Azah Taibu are $\mathrm{PhD}$ candidates at Kampala International University. 